\title{
Aksesuar mental foramenin konik-ışınlı bilgisayarlı tomografi ile görüntülenmesi: iki olgu bildirimi
}

\author{
Mustafa Gümüşok, ${ }^{*}$ Zühre Zafersoy Akarslan, \\ Özlem Üçok \\ Ağız, Diş ve Çene Radyolojisi Anabilim Dalı, Gazi \\ Üniversitesi Diş Hekimliği Fakültesi, Ankara, Türkiye
}

\section{Özet}

TANITIM: Mental foramen mandibulanın önemli anatomik yapılarındandır. Bazı bireylerde mental foramen birden fazla sayıda olabilmekte ve böyle vakalarda aksesuar mental foramen olarak adlandırılmaktadır. Aksesuar mental foramenler, mental foramene kıyasla daha küçük boyutlarda olmalarından dolayı genellikle geleneksel yöntemlerle görüntüleme esnasında teşhis edilememektedir. Konik-ışınlı bilgisayarlı tomografi, maksillofasiyal bölgedeki yapıların radyografik görüntülerinin her üç ortogonal düzlemde magnifikasyonsuz ve distorsiyonsuz elde edilmesini sağlayan bir tekniktir. Bu nedenle geleneksel radyografik tekniklere göre aksesuar mental foramen gibi anatomik yapıların teşhisinde başarılıdır.

OLGU BiLDiRimi: Bu olgu bildiriminde birisi 27 diğeri 59 yaşında olan ve konik-ışınlı bilgisayarlı tomografi görüntülerinde mandibulanın sol tarafında aksesuar mental foramen izlenen iki kadın hasta rapor edilmektedir.

Sonuç: Konik-ışınlı bilgisayarlı tomografi ile aksesuar mental foramenlerin görüntülenmesi, cerrahi işlemlere bağlı gelişebilecek parestezi ve kanama gibi komplikasyonların önlenmesinde önemli rol oynayacaktır.

ANAHTAR Kelimeler: Aksesuar mental foramen; konikışınlı bilgisayarlı tomografi; mandibula; mental foramen; radyografi

Kaynak Göstermek İçin: Gümüşok M, Zafersoy Akarslan Z, Üçok Ö. Aksesuar mental foramenin konik-ışınlı bilgisayarlı tomografi ile görüntülenmesi: iki olgu bildirimi Acta Odontol Turc 2015;32(2):81-4

YAYIN HAKKI: (c) 2015 Gümüşok ve ark. Bu eserin yayın hakkı Creative Commons Attribution License ile ruhsatlandırılmıştır. Sınırsız kullanım, dağıtım ve her türlü ortamda çoğaltım, yazarlar ve kaynağın belirtilmesi kaydıyla serbesttir.

[Abstract in English is at the end of the manuscript]

Makale gönderiliș tarihi: 23 Eylül 2013; Yayına kabul tarihi: 17 Aralık 2013 *iletişim: Mustafa Gümüşok, Ağız Diş ve Çene Radyolojisi Anabilim Dalı, Gazi Üniversitesi Diş Hekimliği Fakültesi, 82. sokak, 06510, Emek, Ankara, Türkiye; e-posta: mustafagumusok@ hotmail.com

\section{Giriş}

Mental sinir, trigeminal sinirin mandibular dalının terminal dalı olan somatik, afferent bir duyu siniridir. ${ }^{1}$ Bu sinir genellikle $1 \mathrm{~mm}$ çaplarında üç dal şeklinde mental foramenden çıkar. ${ }^{2}$ Birinci dal mental bölge derisinin duyusunu alırken diğer dalları ise ikinci premolar dişlere kadar alt dudak derisi, mukoz membranlar ve gingivanın duyusunu alır. ${ }^{3}$

Mental foramen premolar dişler bölgesinde lokalize olup, radyografik görüntülerde yuvarlak veya oval, tek, bilateral, radyolüsensi olarak izlenir. ${ }^{4}$ Nadir olarak mental foramen birden fazla sayıda oluşabilir. Mandibulada birden fazla bulunan mental foramenlerden bir tanesi mental foramen olarak, diğerleri ise aksesuar mental foramen olarak adlandırılır. ${ }^{5}$

Aksesuar mental foramenlerin boyutları genellikle 1 mm'den küçüktür. Bundan dolayı intraoral ve panoramik radyograflarda izlenmeyebilirler. ${ }^{6}$ Yüksek çözünürlüklü konik-ışınlı bilgisayarlı tomografi cihazlarıyla alınan görüntüler anatomik yapıların distorsiyonsuz ve detaylı görüntülenmesini sağladığından, bu teknik ile diğer radyografik yöntemlerle izlenemeyen aksesuar mental foramenler izlenebilmektedir. ${ }^{7}$

Diş hekimliği pratiğinde anatomik varyasyonların tedaviden önce radyolojik olarak belirlenmesi, yapılacak işlemlerin başarısında etkin rol oynamaktadır. Bu nedenle anestezi işlemi ve cerrahi işlemler öncesinde aksesuar mental foramenlerin belirlenmesi tedavinin başarısı ve ortaya çıkabilecek komplikasyonların önlenmesinde önemlidir. ${ }^{3}$

Bu makalenin amacı, 27 ve 59 yaşında iki kadın hastanın başka nedenlerden dolayı çekilen konik-ışınlı bilgisayarlı tomografi görüntülerinde izlenen aksesuar mental foramenleri sunmaktır.

\section{Olgu Bildirimi}

\section{Olgu 1}

27 yaşındaki kadın hasta radyoloji kliniğine mandibulada odontoma ön tanısıyla konik-ışınlı bilgisayarlı tomografi çektirmek için başvurdu. Hastadan $90 \mathrm{kVp}, 10 \mathrm{~mA}$, $18.25 \mathrm{sn}, 8.5 \mathrm{~cm}$ genişliği ve $8.5 \mathrm{~cm}$ yüksekliği bulunan 
tarama hacmi ile konik-ışınlı bilgisayarlı tomografi görüntüleri çekildi (Planmeca Promax 3D, Helsinki, Finlandiya). Konik-ışınlı bilgisayarlı tomografi kesitlerinde ve üç-boyutlu reformat görüntülerinde sol tarafta mental foramenin hemen altında mandibular kanal ile ilişkili bukkal kortekse açılan iyi sınırlı aksesuar mental foramen izlendi (Resim 1).

\section{Olgu 2}

59 yaşındaki kadın hasta radyoloji kliniğine mandibulada lokalize radyoopak lezyonun değerlendirilmesi için konik-ışınlı bilgisayarlı tomografi çektirmek için başvurdu. Hastadan $90 \mathrm{kVp}, 12 \mathrm{~mA}, 13,84 \mathrm{sn}, 8,5 \mathrm{~cm}$ genişliği ve $8,5 \mathrm{~cm}$ yüksekliği bulunan tarama hacmi ile konik-ışınlı bilgisayarlı tomografi görüntüleri çekildi (Planmeca Promax 3D). Konik-ışınlı bilgisayarlı tomografi kesitlerinde ve üç boyutlu reformat görüntüle-

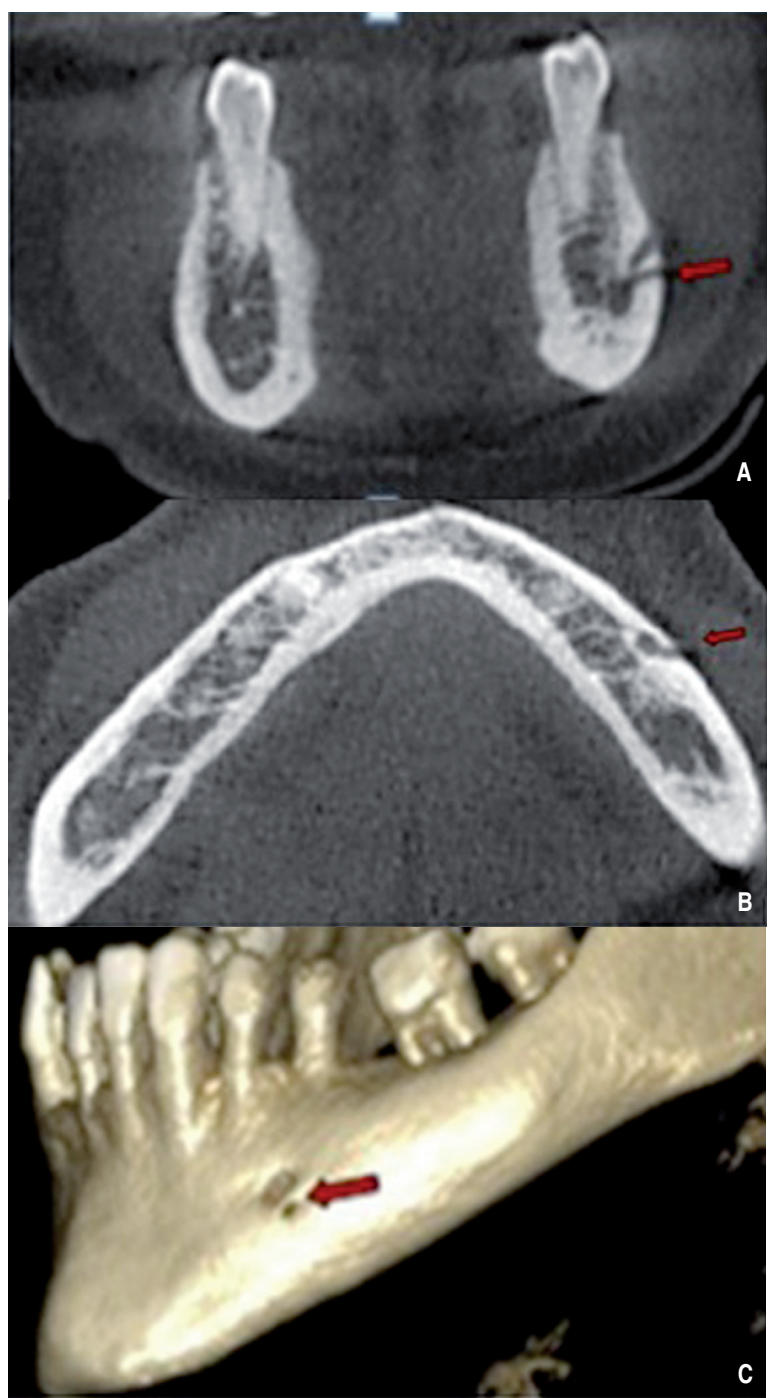

Resim 1. Birinci olgunun konik ışınlı bilgisayarlı tomografi görüntülerinde A: koronal kesitte, B: aksiyal kesitte, C: üç-boyutlu reformat görüntüde izlenen aksesuar mental foramen.

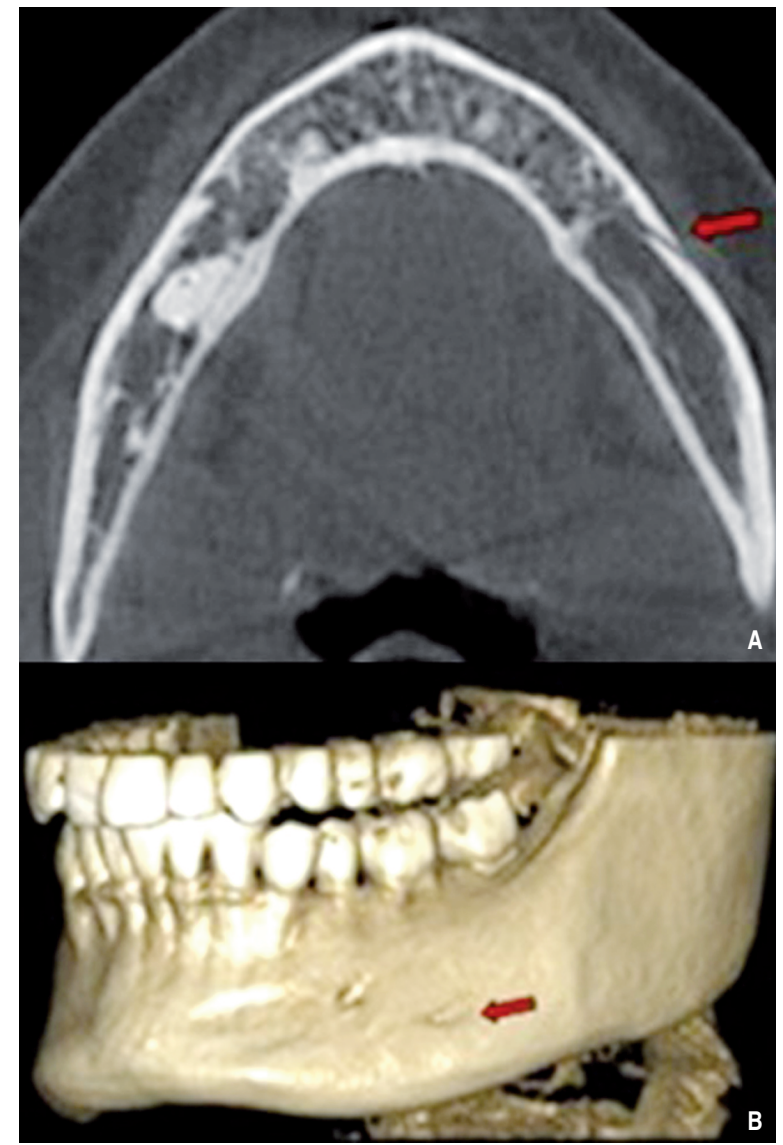

Resim 2. ikinci olgunun konik ışınlı bilgisayarlı tomografi görüntülerinde A: aksiyal kesitte, B: üç-boyutlu reformat görüntüde izlenen aksesuar mental foramen

rinde sol tarafta mental foramenin postero-inferiorunda 1. molar diş hizasında mandibular kanal ile ilişkili bukkal kortekse açılan iyi sınırlı aksesuar mental foramen izlendi (Resim 2).

Her iki hastadan da konik ışınlı bilgisayarlı tomografi görüntüleri çekilmeden önce imzalı onam formu alındı ve hastalara kurşun önlük giydirildi.

\section{TARTIȘMA}

Aksesuar mental foramenler sık görülmeyen oluşumlardır ve görülme sıklığı ırka bağlı olarak değişmektedir. Sawyer ve ark. ${ }^{8}$ dört farklı popülasyon üzerinde yaptıkları çalışmada, Beyaz Amerikalılar arasında \%1.4, Asyalı Hindistanlılar arasında \%1.5, Afrikalı Amerikalılar arasında \%5.7, Nazka yerlileri arasında $\% 9$ oranlarında görüldüğünü göstermişlerdir. Katakami ve ark. ${ }^{6} 150$ hastanın konik-ışınlı bilgisayarlı tomografi görüntüleri üzerinde yaptıkları çalışmada 16 hastada 17 adet aksesuar mental foramen, Naitoh ve ark. ${ }^{9}$ da 157 adet konik ışınlı bilgisayarlı tomografi görüntüsü üzerinde yaptıkları çalışmada $\% 7$ oranında aksesuar mental foramen izlediklerini bildirmişlerdir. Al-Khateeb, ${ }^{10}$ Ürdün populasyonuna ait 860 panoramik rad- 
yograf üzerinde yaptığı çalışmada \%10 oranında aksesuar mental foramen olduğunu göstermişlerdir. Türk toplumunda yapılan çalışmalar incelendiğinde, Kalender ve ark. ${ }^{7} 386$ adet konik ışınlı bilgisayarlı tomografi görüntüsünde \%6.5 oranında, Göregen ve ark. ${ }^{11} \mathrm{da}$ 315 adet konik ışınlı bilgisayarlı tomografi görüntüsünde $\% 6,3$ oranında aksesuar mental foramen görüldüğünü bildirmişlerdir. Bununla birlikte, mental foramenin nadir olarak mandibulada hiç görülmediği de bildirilmiştir; Freitas ve ark. ${ }^{12} 1435$ kuru kafa üzerinde yaptıkları çalışmada, bir tanesi sağ ve sol, bir değeri ise sadece sol olmak üzere 2 kafa iskeleti üzerinde mental foramene rastlamamışlardır.

Aksesuar mental foramenlerin ayırıcı tanısının beslenme kanalı olarak adlandırılan bukkal foramenler ile yapılması gerekmektedir. Bukkal foramenlerin mandibular kanal ile ilişkisi bulunmamakla birlikte, aksesuar mental foramenler mandibular kanalla ilişkili oluşumlardır. ${ }^{9}$ Bizim vakalarımızda da konik ışınlı bilgisayarlı tomografi görüntülerinde, her iki aksesuar mental foramenin mandibular kanalla ilişkili olduğu saptanarak, beslenme kanalları ile ayırıcı tanısı yapıldı.

Aksesuar mental foramenler mental foramene göre genellikle daha küçük boyuttadır. Yapılan çalışmalarda mental foramenin çapı genellikle 2.38 ile $2.64 \mathrm{~mm}$ arasında değişirken, ${ }^{11}$ aksesuar mental foramenin çapının 0.74-0.89 mm arasında değiştiği gösterilmiştir. ${ }^{13}$ Bizim vakamızdaki aksesuar mental foramenler de mental foramenlerden daha küçük boyutta idi.

Aksesuar mental foramenler, genellikle birinci molar dişlerin apikali civarında ve mental foramenin posterioinferiorunda lokalize olup bukkale açılmaktadır. ${ }^{6} \mathrm{Bu}-$ nunla birlikte nadir olarak linguale açılan vakalar da saptanmıştır. ${ }^{4}$ Burada rapor edilen birinci vakadaki aksesuar mental foramen, premolar dişler bölgesinde mental foramenin hemen altında konumlanarak bukkale açılmaktaydı. İkinci vakada ise aksesuar mental foramen mental foramenin posterio-inferioru ve 1. molar diş köküne yakın konumlanarak bukkale açılmaktaydı.

Aksesuar mental foramenlerin teşhisinde panoramik radyografi gibi iki-boyutlu ve konik ışınlı bilgisayarı tomografi gibi üç-boyutlu görüntülerin elde edildiği radyografik teknikler kullanılmaktadır. Konik ışınıı bilgisayarıı tomografi ile medikal bilgisayarlı tomografi cihazlarına oranla daha az radyasyon dozu ile tek rotasyonda, submilimetre çözünürlüğe sahip, teşhis kalitesi yüksek görüntüler elde edilebilmektedir. Ayrıca aksiyal, koronal, sagital düzlemlerde görüntü elde edilebildiği gibi, hacim oluşturma özelliği sayesinde elde edilen veriler ile üç boyutlu görüntülere dönüştürülebilmektedir. ${ }^{14}$ Panoramik radyografi ve konik ışınlı bilgisayarlı tomografi tekniğinin aksesuar mental foramenlerin görüntülenmesindeki etkinliğini karşılaştıran çalışmalarda konik ışınlı bilgisayarlı tomografinin panoramik radyografiye oranla daha başarılı olduğu bildirilmiştir. ${ }^{15,16}$ Bununla birlikte, konik ışınlı bilgisayarlı tomografi tekniğinde kullanılan radyasyon dozunun konvansiyonel tekniğe göre daha yüksek olmasından dolayı bu teknik sadece elde edilecek radyografik bilginin tedaviden elde edilecek yararı artıracağı durumlarda kullanılmalıdır. ${ }^{17}$

\section{SONUÇ}

Mandibulada mental foramen bölgesine yapılacak anestezi ve kemik içi implant uygulamaları, osteotomi, flep operasyonu gibi cerrahi işlemler öncesinde aksesuar mental foramen varyasyonlarının olup olmadığının belirlenmesi, dental anestezide başarının sağlanması ve parestezi, kanama gibi komplikasyonların önlenmesinde büyük önem taşımaktadır. Konik ışınlı bilgisayarlı tomografi, aksesuar mental foramenlerin teşhis edilmesinde etkin bir görüntüleme yöntemidir.

Çıkar çatışması: Yazarlar bu çalışmayla ilgili herhangi bir çıkar çatışmalarının bulunmadığını bildirmiş̧lerdir.

\section{TeșeKKür Ve ANMA}

Bu olgu bildirimi, 25-28 Nisan 2013 tarihinde Erzurum'da düzenlenen Oral Diagnoz ve Maksillofasiyal Radyoloji Derneği 5. Bilimsel Sempozyumunda poster olarak sunulmuştur.

\section{KAYNAKLAR}

1. De Andrade E, Otomo-Corgel J, Pucher J, Ranganath KA, St George $\mathrm{N} \mathrm{Jr}$. The intraosseous course of the mandibular incisive nerve in the mandibular symphysis. Int J Periodontics Restorative Dent 2001;21:591-7.

2. Mraiwa N, Jacobs R, Moerman $P$, Lambrichts I, van Steenberghe D, Quirynen M. Presence and course of the incisive canal in the human mandibular interforaminal region: two-dimensional imaging versus anatomical observations. Surg Radiol Anat 2003;25:416-23.

3. Greenstein G, Tarnow D. The mental foramen and nerve: clinical and anatomical factors related to dental Implant placement: a literature review. J Periodontol 2006;77:1933-43.

4. Neves FS, Torres MG, Oliveira C, Campos PS, Crusoé-Rebello I. Lingual accessory mental foramen: a report of an extremely rare anatomical variation. J Oral Sci 2010;52:501-3.

5. Kaufman E, Serman NJ, Wang PD. Bilateral mandibular accessory foramina and canals: a case report and review of the literature. Dentomaxillofac Radiol 2000;29:170-5.

6. Katakami K, Mishima A, Shiozaki K, Shimoda S, Hamada Y, Kobayashi K. Characteristics of accessory mental foramina observed on limited cone-beam computed tomography. J Endod 2008;34:1441-5.

7. Kalender A, Orhan K, Aksoy U. Evaluation of the mental foramen and accessory mental foramen in Turkish patients using cone-beam computed tomography images reconstructed from a volumetric rendering program. Clin Anat 2012;25:584-92.

8. Sawyer DR, Kiely ML, Pyle MA. The frequency of accessory mental foramina in four ethnic groups. Arch Oral Biol 1998;43:417-20.

9. Naitoh M, Hiraiwa Y, Aimiya H, Gotoh K, Ariji E. Accessory mental foramen assessment using cone-beam computed tomography. Oral Surg Oral Med Oral Pathol Oral Radiol Endod 2009;107:289-94. 
10. Al-Khateeb T, Al-Hadi Hamasha A, Ababneh KT. Position of the mental foramen in a northern regional Jordanian population. Surg Radiol Anat 2007;29:231-7.

11. Göregen M, Miloğlu Ö, Ersoy İ, Bayrakdar iş, Akgül HM. The assessment of accessory mental foramina using cone-beam computed tomography. Turk J Med Sci 2013;43:479-83.

12. de Freitas V, Madeira MC, Toledo Filho JL, Chagas CF. Absence of the mental foramen in dry human mandibles. Acta Anat (Basel) 1979;104:353-5.

13. Toh H, Kodama J, Yanagisako M, Ohmori T. Anatomical study of the accessory mental foramen and the distribution of its nerve. Okajimas Folia Anat Jpn 1992;69:85-8

14. Scarfe WC, Farman AG. What is cone-beam CT and how does it work? Dent Clin North Am 2008;52:707-30.

15. Naitoh M, Yoshida K, Nakahara K, Gotoh K, Ariji E. Demonstration of the accessory mental foramen using rotational panoramic radiography compared with cone-beam computed tomography. Clin Oral Implants Res 2011;22:1415-9.

16. Imada TS, Fernandes LM, Centurion BS, de Oliveira-Santos C, Honório HM, Rubira-Bullen IR. Accessory mental foramina: prevalence, position and diameter assessed by cone-beam computed tomography and digital panoramic radiographs. Clin Oral Implants Res 2014;25:e949.

17. Orhan Al, Orhan K, Aksoy S, Ozgül O, Horasan S, Arslan A, et al. Evaluation of perimandibular neurovascularization with accessory mental foramina using cone-beam computed tomography in children. J Craniofac Surg 2013;24:e365-9.

\section{Imaging of accessory mental foramen with cone-beam computerized tomography: two case reports}

\begin{abstract}
INTRODUCTION: Mental foramen is an important anatomic structure of the mandible. Mental foramen may be presented as more than one in some individuals and named as accessory mental foramen in such cases. Compared to mental foramen, accessory mental foramens are smaller in dimension and because of this, they may remain undetected with conventional imaging modalities. Cone-beam computerized tomography is a technique providing radiographic images of the three orthogonal planes of the maxillofacial region without magnification and distortion. Thus, compared with conventional radiographic techniques, it is more successful in the diagnosis of anatomic structures such as the accessory mental foramen.
\end{abstract}

CAse Report: Two female patients, one aged 27 and the other aged 59, presenting accessory mental foramen on cone-beam computerized tomography images on the left side of the mandible were presented in this article.

ConcLusion: The visualization of accessory mental foramens with cone-beam computerized tomography has an important role in preventing complications like paresthesia and bleeding during surgical procedures.

KEYwORDS: Accessory mental foramen; cone-beam computerized tomography; mandible; mental foramen; radiography 